\title{
Article
}

\section{An inductive force sensor for in-shoe plantar normal and shear load measurement}

Wang, L, Jones, D, Chapman, Graham, Siddle, H, Russel, D, Alazmani, A and Culmer, $\mathrm{P}$

Available at http://clok.uclan.ac.uk/33839/

Wang, L, Jones, D, Chapman, Graham ORCID: 0000-0003-3983-6641, Siddle, $H$, Russel, D, Alazmani, A and Culmer, P (2020) An inductive force sensor for in-shoe plantar normal and shear load measurement. IEEE Sensors Journal, 20 (22). pp. 13318-13331. ISSN 1530-437X

It is advisable to refer to the publisher's version if you intend to cite from the work. https://doi.org/10.1109/JSEN.2020.3006316

For more information about UCLan's research in this area go to http://www.uclan.ac.uk/researchgroups/ and search for <name of research Group>.

For information about Research generally at UCLan please go to http://www.uclan.ac.uk/research/

All outputs in CLoK are protected by Intellectual Property Rights law, including Copyright law. Copyright, IPR and Moral Rights for the works on this site are retained by the individual authors and/or other copyright owners. Terms and conditions for use of this material are defined in the policies page.

\section{CLoK}

Central Lancashire online Knowledge www.clok.uclan.ac.uk

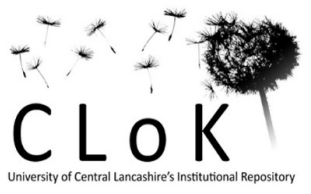




\title{
An Inductive Force Sensor for In-Shoe Plantar Normal and Shear Load Measurement
}

\author{
Lefan Wang, Dominic Jones, Graham J Chapman, Heidi J Siddle, David A Russell, Ali Alazmani, and \\ Peter Culmer
}

\begin{abstract}
Diabetic foot ulcers (DFUs) are a severe global public health issue. Plantar normal and shear load are believed to play an important role in the development of foot ulcers and could be a valuable indicator to improve assessment of DFUs. However, despite their promise, plantar load measurements currently have limited clinical application, primarily due to the lack of reliable measurement techniques particularly for shear load measurements. In this paper we report on the design and evaluation of a novel tri-axis force sensor to measure both normal and shear load on the foot's plantar surface simultaneously. The sensor consists of a group of inductive sensing coils above which a conductive target is placed on a hyperelastic elastomer. Movement of the target under load affects the coil inductances which are measured and digitized by an embedded system. Using a computational finite element model, we investigated the influence of sensing coil form and configuration on sensor performance. A sensor configured with four-square coils and maximal turns provided the best performance for plantar load measurements. A prototype was fabricated and calibrated using a neural network to map the non-linear relationship between the sensor output and the applied tri-axis load. Experimental evaluation indicates that the tri-axis sensor can effectively detect shear load of \pm 16 $\mathrm{N}$ and normal load up to $105 \mathrm{~N}$ (RMS errors: $1.05 \mathrm{~N}$ and 1.73 $\mathrm{N}$ respectively) with a high performance. Overall, this sensor provides a promising basis for plantar normal and shear load measurement which are crucial for improved assessment of DFU.
\end{abstract}

Index Terms-Diabetic foot ulcer, Finite element modelling, Neural network, Plantar normal and shear load, Tri-axis force sensor.

\section{INTRODUCTION}

D IABETES is a major public health concern. Worldwide, 415 million people are living with diabetes, with estimates rising to 642 million ( $10 \%$ of world population) by 2040 [1]. Foot ulceration is a common and devastating complication of diabetes. It can lead to infection, amputation, and even death if timely interventions are not performed, with an approximate $40 \%$ mortality at 5 years in patients with diabetes who underwent amputation [2]. Additionally,

This work was supported by the UK EPSRC under Grant EP/R041776/1. L. Wang, D. Jones, A. Alazmani, and P. Culmer work in the School of Mechanical Engineering, University of Leeds, Leeds LS2 9JT, UK. (e-mail: L.Wang6@leeds.ac.uk, D.P.Jones@leeds.ac.uk, A.Alazmani@leeds.ac.uk, P.R.Culmer@leeds.ac.uk)

G. J. Chapman works in the School of Sport and Health Sciences, University of Central Lancashire, Brook Building (BB132), Preston PR1 2HE, UK. (email: G.J.Chapman@leeds.ac.uk

H. J. Siddle works in the Leeds Institute of Rheumatic and Musculoskeletal Medicine, University of Leeds, Leeds, UK and Podiatry Department, Leeds Teaching Hospitals NHS Trust, Leeds, UK (e-mail: H.Siddle@leeds.ac.uk)

D. A. Russell works in the Leeds Institute of Cardiovascular and Metabolic Medicine, LIGHT Laboratories, University of Leeds, 6 Clarendon Way, Leeds LS2 9NL, UK and Leeds Diabetes Limb Salvage Service, Leeds Teaching Hospitals NHS Trust, Beckett Street, Leeds LS9 7TF, UK (e-mail: davidrussel11@nhs.net) diabetic foot ulcers (DFUs) cause a substantial economic and social burden, with NHS England spending approximately $£ 1.13$ billion on treatment of DFUs in 2014-15 [3], [4]. This figure is expected to rise to $£ 2.1$ billion by $2035 / 6$ [3]. In the US, the annual medical cost for the management of diabetic foot ranges from \$9-13billion.

Elevated or abnormal plantar pressure (the pressure on the sole of the foot) is commonly considered as a major causative factor in the development of DFUs [5]-[8]. However, recent studies indicate that the importance of plantar shear stresses in predication of ulcer formation have been underestimated [9] and that utilizing both pressure and shear stress provides a more effective means to identify and assess abnormal pressure loads associated with DFUs [10]. Measurement of shear stresses is a significant challenge, predominantly due to the conformable nature of the foot's plantar surface and the high load ranges experienced (generally up to $740 \mathrm{kPa}$ (peak pressure) and $140 \mathrm{kPa}$ (peak shear)) [9], [11]-[14].

A variety of commercial systems has been developed to measure plantar loading, including sensing platforms and wearable sensory insoles. Notable examples include Pedar ${ }^{\circledR}$ [15], F-Scan ${ }^{\mathrm{TM}}$ [16], medilogic WLAN insole [17], BioFoot ${ }^{\circledR}$ [18], P-WALK [19], emed ${ }^{\circledR}$ [20], MatSCAN ${ }^{\mathrm{TM}}$ [21], and footscan ${ }^{\circledR}$ [22]. These systems share a common measurement limitation of solely measuring plantar pressure, without the capability of measuring shear stress. The strain gauge based Cleveland Clinic Plate [9], [23] and the camera-based FootSTEPS platform [24] are reported to measure both plantar pressure and shear stress, but they are non-portable, only allowing static and limited dynamic measurements of 1-2 stance phases.

Researchers have attempted to address this situation through a variety of multi-axis sensing modalities including capacitive, resistive, piezoelectric and inductive systems [25]. Multi-axis (typically tri-axis) capacitive sensors generally embed four capacitive elements which can be used to obtain pressure and shear stress through selective decoupling of the output signals. In 2008, Lee et al. [26] reported a $8 \times 8$ triaxis sensing array, each sensor node with a full-scale range of $131 \mathrm{kPa}$ in three directions. In 2015, Liang et al. [27] implemented a $4 \times 4$ sensing array in which each sensor unit has a dimension of $4.0 \mathrm{~mm} \times 4.0 \mathrm{~mm} \times 1.1 \mathrm{~mm}$ and provides a measurement range of $31 \mathrm{kPa}$ and $250 \mathrm{kPa}$ for shear stress and pressure, respectively. Inductive sensors have received increasing attention for monitoring plantar load due to robustness of environmental factors. In 2012, Wattanasarn et al. [28] designed a 3D flexible force sensor consisting of a detection coil layer and an excitation coil layer, each 
layer with four planar square coils. The design was compact $(7.2 \mathrm{~mm} \times 7.2 \mathrm{~mm} \times 2.5 \mathrm{~mm})$ although sensor performance was limited in measurement range $(11.8 \mathrm{kPa}, 11.3 \mathrm{kPa}$, and $15.7 \mathrm{kPa}$ in the $\mathrm{x}^{-}, \mathrm{y}-$, and $\mathrm{z}$-axis, respectively). In 2015, Du et al. [29] implemented a three-coil inductive sensor, one coil sensitive to pressure and the other two sensitive to both pressure and shear stress. The sensor prototype was used to measure the load distribution under the foot during normal gait but the spatial resolution was limited by the large sensor size $(76.2 \mathrm{~mm} \times 76.2 \mathrm{~mm} \times 22 \mathrm{~mm})$. To the best of the authors' knowledge, a sensor capable of providing high-spatial resolution while obtaining multi-axis measurement of plantar pressure and shear stress is not available.

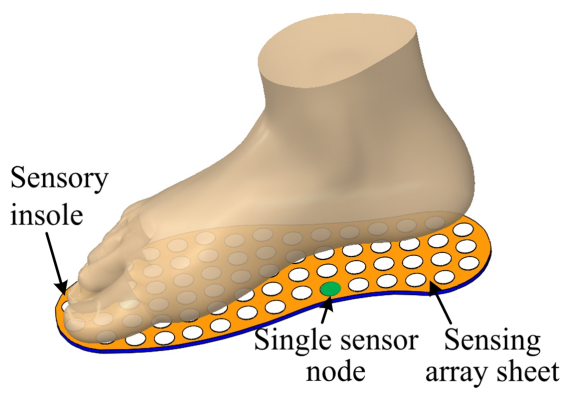

Fig. 1: Illustration of a sensory insole integrated with an array of force sensors for measuring plantar load.

This research aims to develop a tri-axis force sensing unit for measurement of DFU plantar loading, using our previous work in inductive load sensing as a foundation [30], [31]. Our concept is to integrate an array of such sensors within a shoe sole, enabling load mapping across the plantar surface as shown in Fig. 1. This entails optimization of the individual sensing unit to meet the sensing requirements associated with in-shoe measurement of plantar loading in people at risk of diabetic foot ulcers. These aspects are difficult to define due to a lack of appropriate measurement systems and associated plantar loading data. In this context, load requirements have been estimated from pioneering studies using foot force sensing plates capable of shear-load measurement [9], [11]-[14], while sensor size (determining the maximum spatial resolution which can be achieved using a sensing array) is drawn from research-grade in-shoe measurement systems [23], [32]-[34], summarized in Table I.

TABLE I: Sensing requirements for measuring plantar load under diabetic foot.

\begin{tabular}{lll}
\hline Measuring capability & Pressure & $>=740 \mathrm{kPa}$ \\
[9], [11]-[14] & Shear stress $\quad>=140 \mathrm{kPa}$ \\
Recommended measurement surface/ & $<=15 \mathrm{~mm} \times 15 \mathrm{~mm}$ \\
spatial resolution [23], [32]-[34] & $>=50 \mathrm{~Hz}$ \\
Sampling rate [35], [36] & \\
\hline
\end{tabular}

Here we report on optimization and evaluation of the triaxis sensing element for simultaneous measurement of plantar normal and shear load. This represents the first sensor optimized to measure these quantities, engineered to meet a series of clinically-informed requirements listed in Table I. Section II provides an overview of the operating principles then Section III investigates optimization of the inductive coil configuration. This is used as the basis for fabrication of a prototype, reported in Section IV together with methods for calibration and multiaxis experimental evaluation.

\section{PRINCIPLE OF OPERATION}

Sensors using the principle of eddy-current formation are widely used, particularly in non-contact displacement sensing applications. Generally, an eddy-current displacement sensor comprises a sensing coil and a conductor. As an alternating current flows through the coil, a magnetic field is generated surrounding it. If the conductor is brought into the vicinity of the coil, eddy currents will be induced on the conductor's surface. According to Lenz's law, the eddy current creates its own magnetic field that opposes the original field generated by the coil. The coupling between the coil and the conductor causes variations in their inductance and resistance.

A force sensor can be adapted from eddy-current based displacement sensors by adding an elastic medium between the coil and the conductor. As illustrated in Fig. 2(a), when an external force is applied, the elastomer deforms and accordingly the displacement of the conductor (target) changes, thus altering the coil inductance. Provided the conductor has sufficient thickness, it also acts to mask effect of external conductors (e.g. the foot in this application [31]). Recent developments in inductance digitizing integrated circuits (LDCs) [37] enable fast, accurate measurement of this inductance which can then be mapped to applied force. LDCs detect coil inductance by measuring the oscillation frequency of L-C resonators. As shown in Fig. 2(b), a single coil can be modeled by a RLC parallel electrical model, and it forms an L-C resonant oscillator by connecting the coil with an external capacitor $C_{\text {ext }}$. The oscillation frequency varies with the sensor inductance. Once the oscillation frequency is measured by LDCs, the coil inductance can be derived using the following equation.

$$
L=\frac{1}{(2 \pi f)^{2}\left(C_{\text {para }}+C_{\text {ext }}\right)}
$$

where $f$ is the oscillation frequency of the L-C network, $C_{\text {para }}$ is the parasitic capacitance of the coil, and $C_{e x t}$ is an external capacitor. $C_{\text {para }}$ is typically a few picofarads for planar coils of this size [38]-[40] and can thus be neglected as $C_{\text {ext }} \gg$ $C_{\text {para }}$.

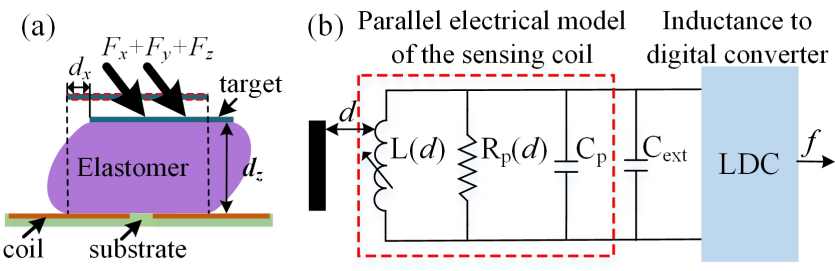

Fig. 2: (a) Illustration of an eddy-current-based tri-axis force sensor, (b) the inductance measurement for a single sensing coil.

Based on this basic transducer mechanism, researchers have proposed and developed tri-axis inductive sensors for various 
(a) Four-coil sensor
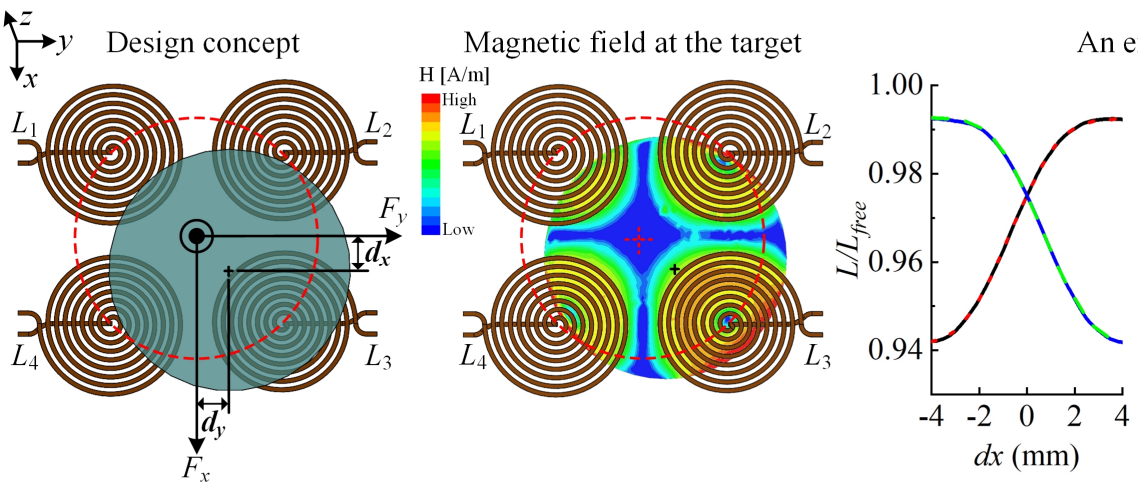

An example of four-coil sensor outputs

(b) Three-coil sensor
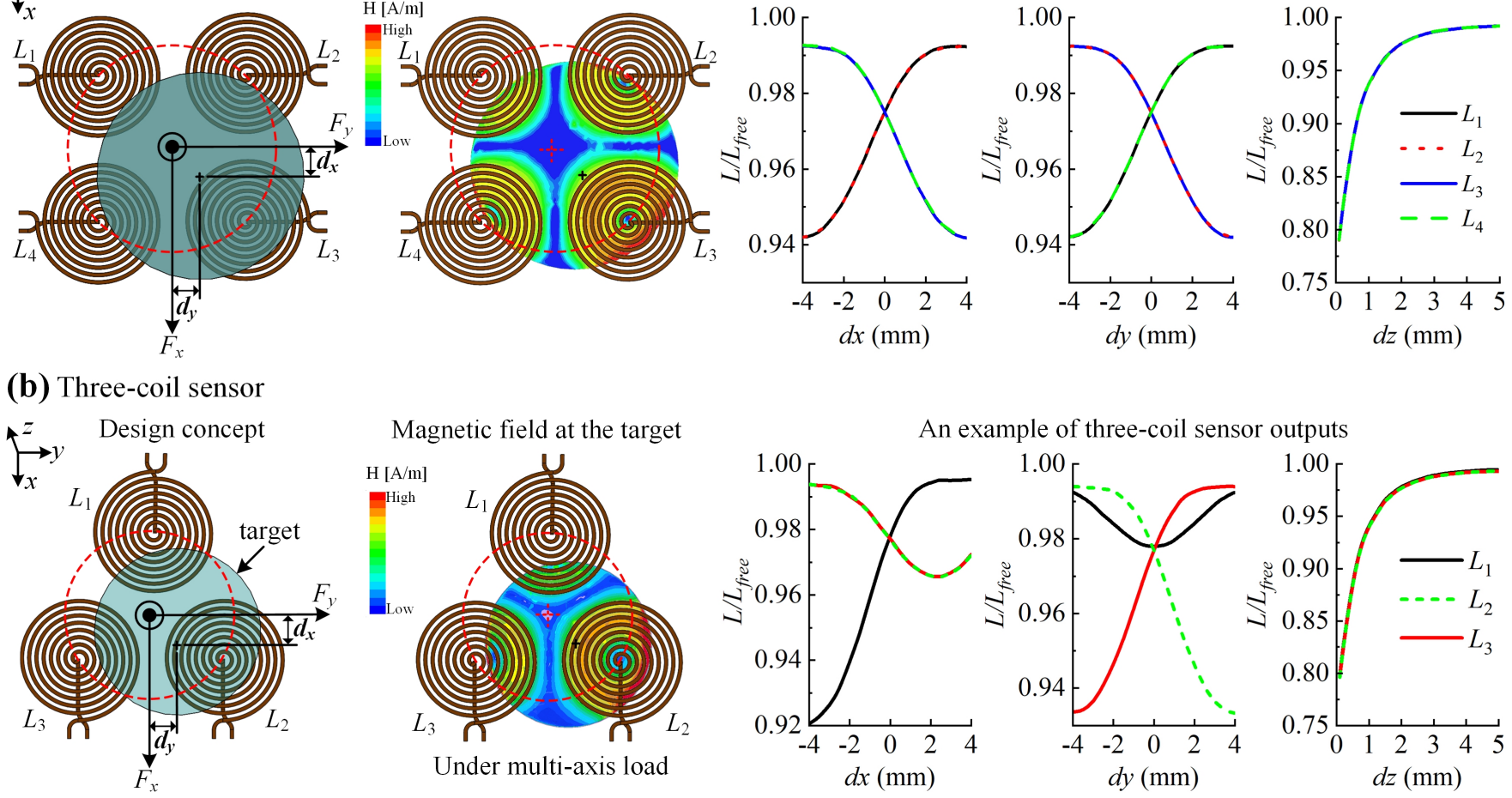

Fig. 3: Schematic, operating principle and representative response of tri-axis inductive force sensors with different configurations; (a) sensor consisting of four symmetric sensing coils; (b) sensor consisting of three coils, $L_{i}$ represents the inductance of coil $i(i=1,2,3,4)$.

multi-axis force measurement applications [28], [29], [31], [41], [42]. In general, the sensor requires one inductive coil per independent measurement axis. For tri-axis sensors, both three and four coils are common, where a four-coil arrangement brings the advantage of an axially symmetric structure. Fig. 3 illustrates their respective operating behavior with simulated responses from the coils generated using a computational simulation described in Section III. For the four-coil sensor, shown in Fig. 3(a), application of a perpendicular force $\left(F_{z}\right)$ moves the target closer to all coils, increasing the magnetic coupling and thus the coil inductances $\left(L_{1}-L_{4}\right)$ will decrease. Applying a shear load $\left(F_{x}\right)$ the magnetic coupling with coils 1 and 2 decreases whilst the coupling with coils 3 and 4 increases. This causes a corresponding increase in $L_{1}$ and $L_{2}$ and decrease in $L_{3}$ and $L_{4}$. The same principle applies to loading along the y-axis. The three-coil arrangement, follows the same mechanisms but differs with a more complex response to shear loading due to its asymmetric coil arrangement, as shown in Fig. 3(b). In both configurations, the relationship between the applied load and coil inductances is coupled and non-linear. Thus to obtain the components of applied force $\left(F_{x}, F_{y}\right.$, and $F_{z}$ ) requires appropriate decoupling calibration methods, as described in sections III and IV.

\section{OPTIMIZATION OF SENSING COIL DESIGN}

The sensing coil plays a key role in the performance of the inductive tri-axis force sensor. The inductance response of the coils is highly dependent on coil geometry. In general, it is desirable to maximize the uncoupled inductance of the coils for a given spatial area which determines the measurement range (i.e. the maximum shift in sensor inductance due to the target movement). The sensitivity of the sensor is then a function of how the coils' baseline inductance changes during interaction with the conductive target. In this section, different coil patterns with different trace width, pitch, and shapes, are investigated to identify the optimal design for plantar load sensing.

\section{A. Effect of Trace Width and Pitch on the Coil Inductance}

Trace width and pitch determine the number of turns of a coil in a specific sensing area and thus affect the coil inductance. To investigate their effect, two widely researched coil topologies, i.e. the circular and the square coils illustrated in Fig. 4, are selected as representatives. Their outer diameters are kept same, i.e. $7 \mathrm{~mm}$. The number of the coil turns is maximized according to the trace width and pitch. The coils inductances are simulated using an FE computational simulation (ANSYS Maxwell 3D module, full details of the model design and simulation are in Appendix A \& B, coil geometries are specified in Appendix C). To simplify the modelling, single-layer coils are used but the results are consistent with multi-layer systems.

The simulated inductances of the circular coil and the square coil are plotted in Fig. 5. It can be seen that they 


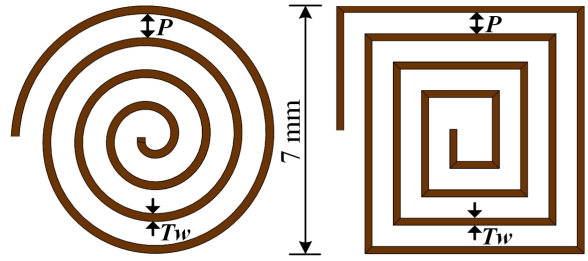

Fig. 4: Examples of coil topologies, with $P$ being the pitch and $T w$ being the trace width.

demonstrate similar trends. As trace width increases, the coil inductance falls at a decreasing rate. With the reduction of pitch, the inductance increases. This can be explained by the fact that the number of coil turns and the total trace length (see Appendix C) reduce with an increase in pitch and trace width. Therefore, to maximize inductance, the coil should be designed to minimize pitch spacing and trace width (to permit more coil turns in a given area). This is typically bounded by current manufacturing constraints in which commercial printed circuit board (PCB) fabrication usually allows pitch and trace width no less than $0.1 \mathrm{~mm}$.

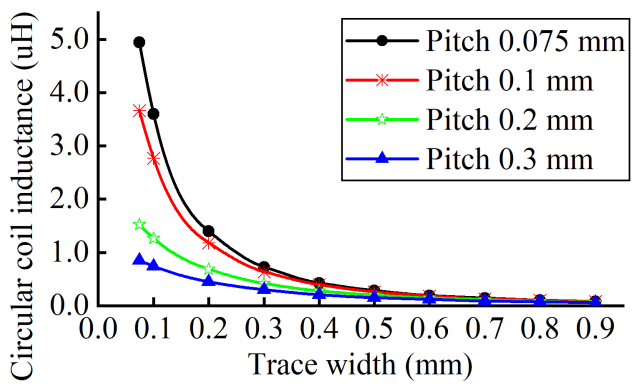

(a) Inductance of circular coil with different trace width and pitch.

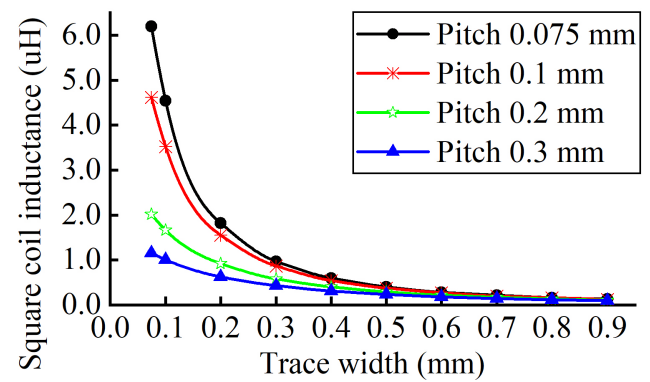

(b) Inductance of square coil with different trace width and pitch.

Fig. 5: The effect of the trace width and pitch to the inductance of the circular and square coils.

\section{B. Planar Coil Topologies of Tri-axis Inductive Sensor}

To allow tessellation of the sensing nodes (e.g. in an insoleshaped sensing array for plantar load measurements), it is advantageous to employ a regular sensing geometry such as a rectangle or circle. The overall sensor size will then determine the spatial resolution which can be achieved. To address the requirements defined in Table $I$, the inductive sensors were designed with a square/circular sensing area of $15 \mathrm{~mm} \times 15$ $\mathrm{mm}$ or $\varnothing 15 \mathrm{~mm}$. As described in section II, the inductive sensors to be studied consist of three or four planar coils.
Three coil shape primitives were selected for investigation in each sensor configuration; circular, square and fan elements for the four-coil sensor design and circular, elliptical and fan coils for the three-coil sensor development. These primitives were identified through preliminary work as the most promising geometries to maximize coil turns and coil length within a particular sensing area. The schematics of the sensors to be studied are shown in Fig. 6. We set the trace width and pitch of the coils as $0.1 \mathrm{~mm}$ to meet typical manufacturing capabilities (see Section III.A). Design guidance for inductive coils specifies that the ratio of the coil's inner diameter $\left(\mathrm{d}_{\mathrm{IN}}\right)$ to outer diameter $\left(\mathrm{d}_{\mathrm{OUT}}\right)$ should be greater than 0.3 for a lower rate of energy loss [43]. This enables four circular coils, each with 12 turns $\left(\mathrm{d}_{\text {OUT }}=7.0 \mathrm{~mm}, \mathrm{~d}_{\mathrm{IN}}=2.2 \mathrm{~mm}\right.$, see Fig. $6(a) \&(b) . i)$. For comparison, the other coil geometries were also designed with 12 turns. In addition, we also investigated the performance where the number of turns was maximized for each coil geometry. To enhance the coil inductance, all the coils shown in Fig. 6 were designed with double layers; the top layer in a clockwise rotation and the bottom layer in an anti-clockwise rotation, so that the magnetic fields positively add.

According to our previous research [31], the circular target passing through the center of all coils enabled the tri-axis inductive sensors to produce comparable sensitivity in all three axes. Therefore, an aluminum circular target is used in this research, sized to bisect the center of each coil under a zero displacement condition $(\varnothing 11.3 \mathrm{~mm}$ for the four-coil inductive sensors and $\varnothing 9.2 \mathrm{~mm}$ for the three-coil sensors, thickness 0.2 $\mathrm{mm})$.

\section{Finite Element Modelling of the Tri-axis Sensors}

An FE method was used to model and investigate the electromagnetic response of the different inductive sensor configurations shown in Fig. 6. Models were constructed in a computational package (ANSYS, see Appendix A) to obtain coil inductance for different axial displacements. The output inductances of all the four-coil sensors respond in a similar way to the example shown in Fig. 3(a) and the outputs of all the three-coil sensors are similar to that presented in Fig. 3(b). With the current spatial parameters, the sensors are generally sensitive to lateral displacements from $-2 \mathrm{~mm}$ to $2 \mathrm{~mm}$ and vertical displacement below $2 \mathrm{~mm}$, which is referred to as the operating volume for the inductive sensors in this paper. To compare the performance of the different sensors within this operating volume, a simplified methodology was used to compute the inductance along each axis, i.e. $L_{x}, L_{y}$, and $L_{z}$. Equation (2) was used to decouple the outputs of the four-coil sensors and equation (3) was for the three-coil sensors. They are similar to the method used in [31], [42].

Four-coil sensor $\left\{\begin{array}{l}L_{x}=-\Delta L_{1}-\Delta L_{2}+\Delta L_{3}+\Delta L_{4} \\ L_{y}=-\Delta L_{1}+\Delta L_{2}+\Delta L_{3}-\Delta L_{4} \\ L_{z}=\left(\Delta L_{1}+\Delta L_{2}+\Delta L_{3}+\Delta L_{4}\right) / 4\end{array}\right.$ 


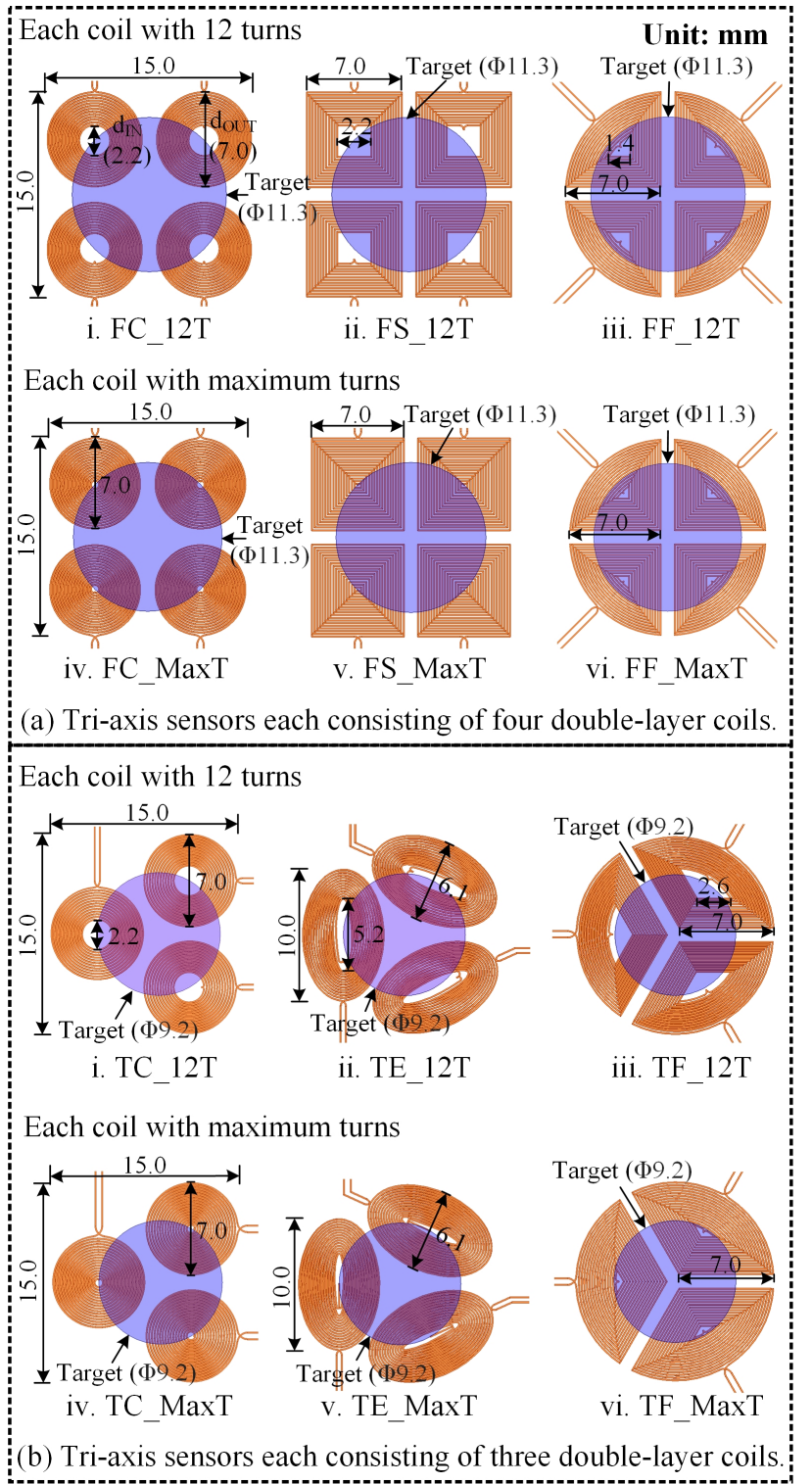

Fig. 6: Planar coil topologies of the tri-axis inductive sensors. (a) Each sensor consists of four double-layer coils, with a total sensing area of $15 \mathrm{~mm} \times 15 \mathrm{~mm}$; (b) each sensor consists of three double-layer coils, with a total sensing area of $15 \mathrm{~mm} \times 15 \mathrm{~mm}$. The abbreviations of 'FC_12T', 'FS_12T', 'FF_12T', 'TC_12T', 'TE_12T', and 'TF_12T' represent the four-circular-coil sensor, the four-squarer-coil sensor, the four-fan-coil sensor, the three-circular-coil sensor, the three-elliptical-coil sensor, and the three-fan-coil sensor with 12 turns, respectively; 'FC_MaxT', 'FS_MaxT', 'FF_MaxT', 'TC_MaxT', 'TE_MaxT', and 'TF_MaxT' represent the four-circular-coil sensor, the four-squarer-coil sensor, the four-fan-coil sensor, the three-circular-coil sensor, the three-elliptical-coil sensor, and the three-fan-coil sensor with the maximum turns, respectively.

Three-coil sensor $\left\{\begin{array}{l}L_{x}=-\Delta L_{1}+\Delta L_{2}+\Delta L_{3} \\ L_{y}=\Delta L_{1}-\Delta L_{2}+\Delta L_{3} \\ L_{z}=\left(\Delta L_{1}+\Delta L_{2}+\Delta L_{3}\right) / 3\end{array}\right.$ where $L_{x}, L_{y}, L_{z}$ denote the inductive output along the x, y-, and z-axis, respectively. $\Delta L_{i}$ represents the difference between the coil output $L_{i}$ and the coil inductance at free space $L_{\text {free_i }}$, i.e. $\Delta L_{i}=L_{\text {free_ } i}-L_{i}(i=1,2,3,4)$.

The axial inductances of each sensor to the axial movements (vertical motion with $d x$ and $d y$ equal to zero and lateral motion with $d z$ equal to $1 \mathrm{~mm}$ ), are computed using (2) or (3). As shown in Fig. 7(a), the four-coil inductive sensors produced almost linear responses to the lateral movements but nonlinear outputs to the vertical motion. Conversely, the threecoil sensors showed linear outputs to the $\mathrm{x}$-axis motion but nonlinear changes to both the $\mathrm{y}$ - and $\mathrm{z}$-axis movements (see Fig. 7(b)). Additionally, the four-coil sensors all demonstrated larger inductance variation to the tri-axis motion of the target in comparison to the three-coil sensors. Among the three-coil sensors, TF_MaxT exhibited the highest inductive changes to all the $\mathrm{x}$-/y-/z-axis motion $(1.1 \mu \mathrm{H}, 0.9 \mu \mathrm{H}$, and $0.5 \mu \mathrm{H}$, respectively), but lower than any one of the proposed fourcoil sensors. Among the four-coil sensors, FS_MaxT showed the largest variations in inductance $(1.8 \mu \mathrm{H})$ to the lateral motion. For vertical movement of the target, FF_MaxT and FF_12T presented comparable inductance change (about 0.8 $\mu \mathrm{H})$, higher than the other sensors.

The sensitivity of the tri-axis inductive sensors was calculated and summarized in Table II. In comparison with the three-coil sensors, the four-coil sensors generally demonstrated higher sensitivity to both the lateral and the vertical movements. Additionally, for a particular sensor configuration, maximizing the coil turns produced a higher sensitivity. Among these sensors, FS_MaxT displays the highest lateral sensitivity but a lower vertical sensitivity. In contrast, FF_MaxT shows the highest vertical sensitivity but a lower lateral sensitivity.

TABLE II: Sensitivity of the tri-axis inductive sensors at the specified motion range.

\begin{tabular}{lccc}
\hline Inductive sensor & $S_{x}(\mathrm{nH} / \mathrm{mm})$ & $S_{y}(\mathrm{nH} / \mathrm{mm})$ & $S_{z}(\mathrm{nH} / \mathrm{mm})$ \\
\hline FC_12T & 355.6 & 355.7 & {$[86.2,566.4]$} \\
FC_MaxT & 392.9 & 393.0 & {$[112.4,736.2]$} \\
FS_12T & 419.1 & 423.8 & {$[72.7,592.0]$} \\
FS_MaxT & $\mathbf{4 8 9 . 1}$ & $\mathbf{4 9 4 . 6}$ & {$[74.1,644.1]$} \\
FF_12T & 353.1 & 353.1 & {$[179.6,1169.9]$} \\
FF_MaxT & 358.3 & 358.1 & {$[\mathbf{1 8 7 . 1}, \mathbf{1 2 1 0 . 0}]$} \\
TC_12T & 214.5 & {$[71.7,297.3]$} & {$[85.0,555.4]$} \\
TC_MaxT & 236.1 & {$[81.5,323.6]$} & {$[108.1,716.5]$} \\
TE_12T & 251.9 & {$[56.9,365.5]$} & {$[44.5,382.6]$} \\
TE_MaxT & 289.8 & {$[69.5,419.7]$} & {$[40.8,415.9]$} \\
TF_12T & 265.3 & {$[96.3,362.9]$} & {$[56.6,502.1]$} \\
TF_MaxT & 294.1 & {$[115.0,396.9]$} & {$[71.2,579.4]$} \\
\hline
\end{tabular}

The maximum and the minimum values of the inductance, the quality factor $(Q)$, and the equivalent parallel resistance $(R p)$ of each coil pattern are presented in Table III. $Q$ is a measure of a coil's efficiency and $R p$ determines the drive current required for a measurable oscillating amplitude, which are defined in (4).

$$
\begin{aligned}
& R p=\frac{(2 \pi f L)^{2}}{R s} \\
& Q=\frac{2 \pi f L}{R s}=\frac{R p}{2 \pi f L}
\end{aligned}
$$


(a) The four-coil sensors' responses.

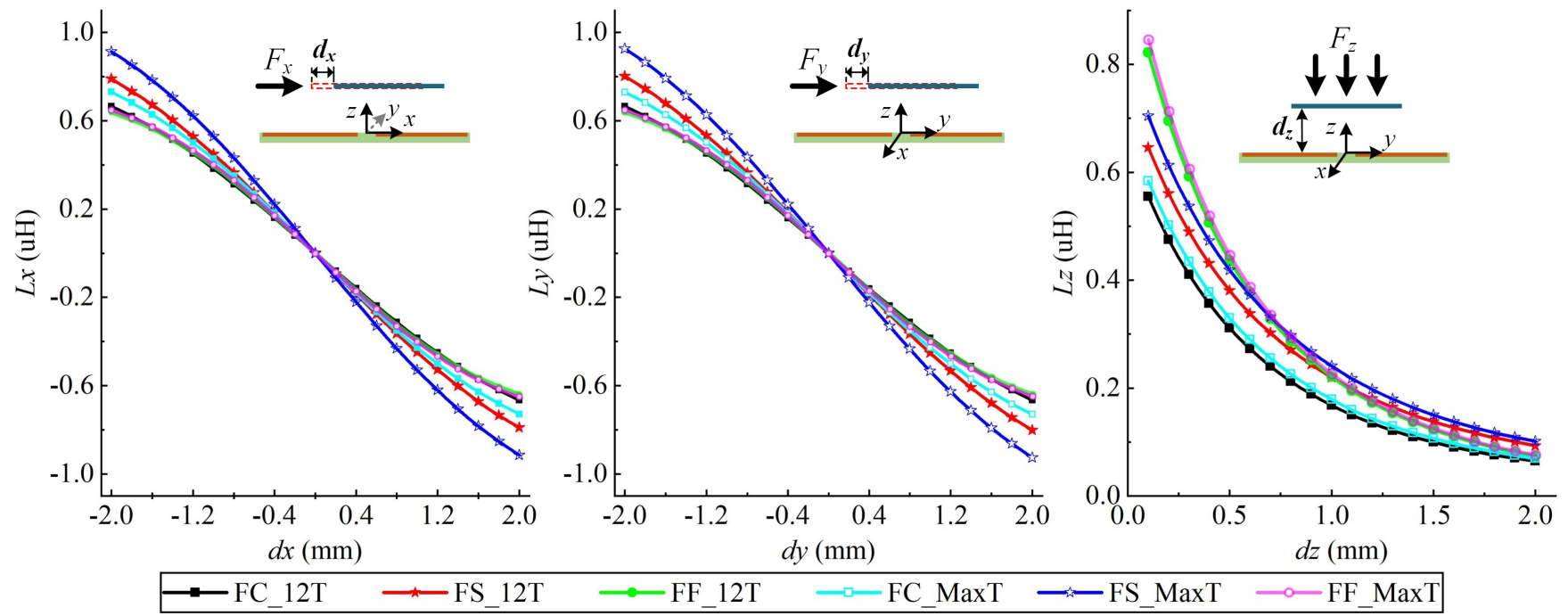

(b) The three-coil sensors' responses.

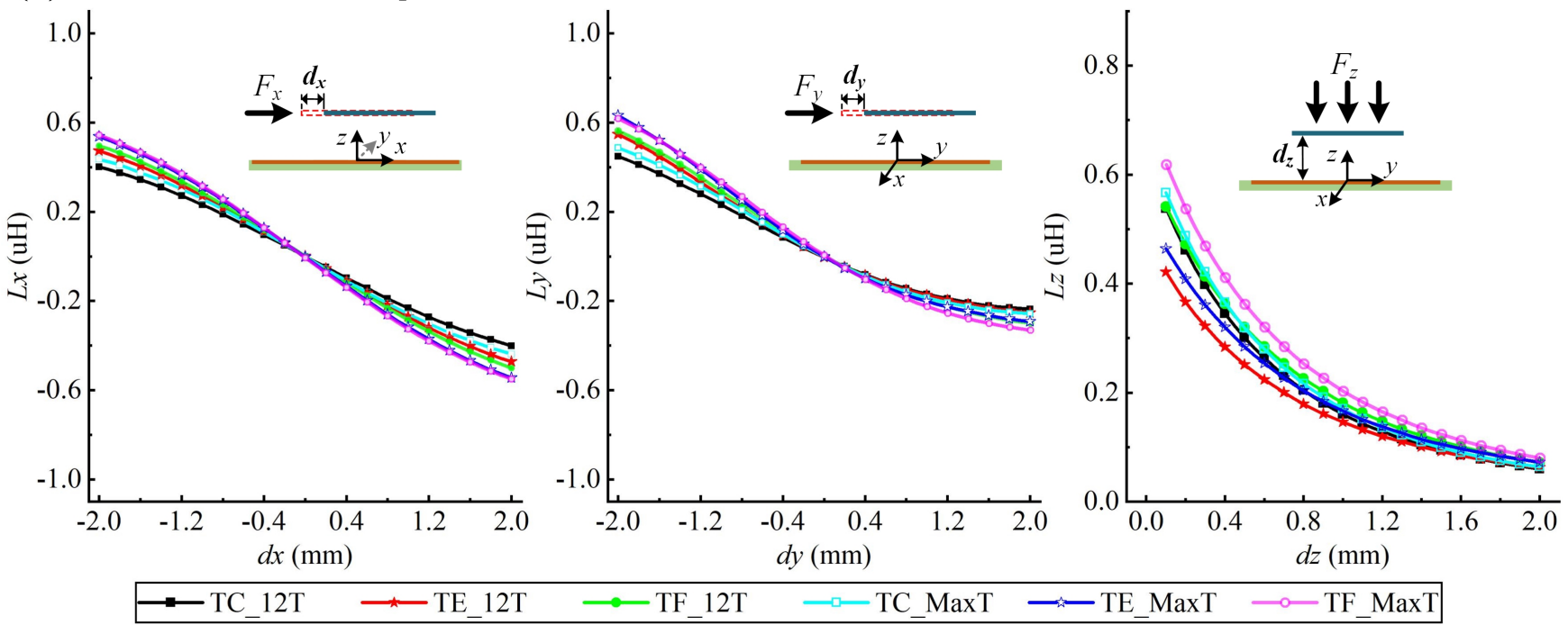

Fig. 7: The inductive responses of the proposed sensors to the tri-axis movement of the target.

where $R s$ and $L$ represent the series resistance and the inductance of coil, respectively. The parameter $f$ denotes the operating frequency.

Each sensing coil produces the largest $L, R p$, and $Q$ at the operating frequency when at free space (i.e. without target); in the operating volume, the minimum values of $L, R p$, and $Q$ are generated as the coil has the maximum overlapping with the target. Table III shows that for any configuration, using maximal coil turns produces higher inductance but lower parallel resistance $R p$ and quality factor $Q$ than a 12-turn equivalent. This occurs because the coil's innermost turns contribute less to the overall inductance than the outer turns but still increase the equivalent series resistance $R s$, thus decreasing $R p$ and $Q$. Among these sensors, FF_12T and FF_MaxT demonstrated the lowest $R p$ and $Q$, indicating a high-energy dissipation; the four-square-coil sensors (FS_12T and FS_MaxT) and the three-fan-coil sensors (TF_12T and
TF_MaxT) presented comparable values of $R p$ and $Q$, generally higher than the others, showing their great capability of energy storage.

Overall, considering factors of baseline inductance, target sensitivity, and Q factor, the four-coil sensors consistently outperform the three-coil sensors for tri-axis motion. From the proposed twelve tri-axis sensor designs, FS_MaxT is best suited to measure plantar load distribution due to its high sensitivity, low energy dissipation, and low current required to maintain oscillation.

\section{SENSOR FABRICATION AND EVALUATION}

\section{A. Sensor Prototyping}

An inductive tri-axis force sensor was developed from the ideal configuration (FS_MaxT) identified in section III. The design consists of four-square double-layer coils. The coils were fabricated on a 25 um thick Kapton polyimide film using 
TABLE III: The inductance, the AC parallel resistance $R p$ and the quality factor $Q$ of each sensor at a typical operating frequency of $6.2 \mathrm{MHz}$.

\begin{tabular}{lcccccc}
\hline \multirow{2}{*}{ Sensor } & \multicolumn{3}{c}{ Maximum } & \multicolumn{3}{c}{ Minimum } \\
\cline { 2 - 7 } & $\mathrm{L}(\mu \mathrm{H})$ & $\mathrm{Rp}(\mathrm{k} \Omega)$ & $\mathrm{Q}$ & $\mathrm{L}(\mu \mathrm{H})$ & $\mathrm{Rp}(\mathrm{k} \Omega)$ & $\mathrm{Q}$ \\
\hline FC_12T & 2.56 & 4.06 & 50.5 & 0.66 & 0.16 & 8.0 \\
FC_MaxT & 2.78 & 3.87 & 44.3 & 0.70 & 0.17 & 7.8 \\
FS_12T & 3.13 & 5.00 & 50.6 & 0.91 & 0.26 & 9.0 \\
FS_MaxT & 3.51 & 5.05 & 45.8 & 0.99 & 0.27 & 8.8 \\
FF_12T & 2.14 & 2.66 & 39.6 & 0.55 & 0.12 & 7.0 \\
FF_MaxT & 2.18 & 2.64 & 38.6 & 0.56 & 0.12 & 7.0 \\
TC_12T & 2.57 & 3.93 & 48.7 & 0.57 & 0.13 & 7.0 \\
TC_MaxT & 2.79 & 3.84 & 43.9 & 0.63 & 0.14 & 7.1 \\
TE_12T & 3.26 & 5.15 & 50.4 & 0.82 & 0.20 & 7.8 \\
TE_MaxT & 3.69 & 5.54 & 47.9 & 0.91 & 0.22 & 7.8 \\
TF_12T & 3.26 & 4.93 & 48.1 & 0.94 & 0.26 & 8.7 \\
TF_MaxT & 3.52 & 4.94 & 44.6 & 1.00 & 0.27 & 8.6 \\
\hline
\end{tabular}

a standard flexible PCB manufacturing process, located in an area of $15.0 \mathrm{~mm} \times 15.0 \mathrm{~mm}$ and with a total thickness of 0.23 $\mathrm{mm}$, as shown in Fig. 8. A circular aluminum disc $(\varnothing 11.3 \mathrm{~mm}$, thickness $0.2 \mathrm{~mm}$ ) was laser-cut as the sensing target. A 2-mm thick silicon sheet (Smooth-Sil ${ }^{\mathrm{TM}}$ 950, Smooth-On Inc., USA) was selected as the elastic medium between the coils with the target due to its mechanical properties providing appropriate response under loading [44]. For the silicon fabrication, first, two parts of the silicon liquids (10A:1B weight) were mixed and deaerated using a non-vacuum mixer (ARE-310, Thinky Inc., Japan). Then, the mixture was poured into an acrylic mold with a 2-mm thickness. Once the silicon was spread uniformly, it was left at the room temperature to cure. A circular elastomer $(\varnothing 11.3 \mathrm{~mm})$ was then cut from the sheet using a laser-cutter (VLS3.50, Universal Laser Systems).

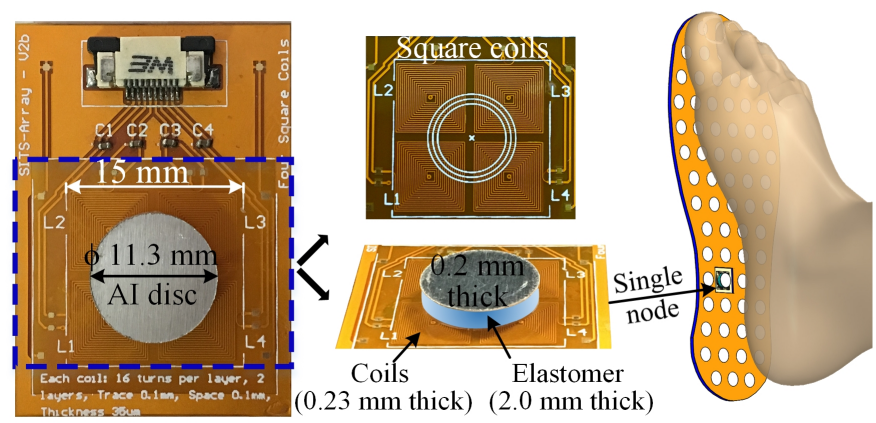

Fig. 8: An integrated tri-axis inductive sensor prototype.

The sensor was finally assembled using cyanoacrylate glue to affix conjoined layers and alignment masks to ensure precise alignment of the target and elastomer relative to the coils. Fig. 8 shows an assembled prototype of the resultant tri-axis inductive force sensor.

\section{B. Electronic Interface}

To obtain the external load applied to the sensor, the coils' inductances need to be measured and post-processed. As described in section II, a four-channel inductance to digital converter chip (LDC1614, Texas Instruments, USA) was used to drive the L-C circuit and measure its oscillation frequency (see the schematics shown in Fig. 9). This chip is capable of operating at an oscillation frequency of $1 \mathrm{kHz}$ to $10 \mathrm{MHz}$. In the operating volume of the tri-axis sensor prototype, the minimum inductance of each square coil is $0.99 \mu \mathrm{H}$. Thus, to keep the coil oscillation below $10 \mathrm{MHz}$, an external capacitor with a minimum capacitance of $256 \mathrm{pF}$ is required. A 330 $\mathrm{pF}$ C0G/NP0 capacitor was selected for this purpose (from typical capacitance values), resulting in an L-C circuit which resonates at a frequency ranging from $4.7 \mathrm{MHz}$ (maximum inductance $3.51 \mu \mathrm{H}$, without loading) to $8.8 \mathrm{MHz}$ (minimum inductance, fully loaded) during the multi-axis motion. A realtime embedded evaluation board (NI MyRIO-1900 [45]) was used to communicate with the LDC1614 through an I2C bus.

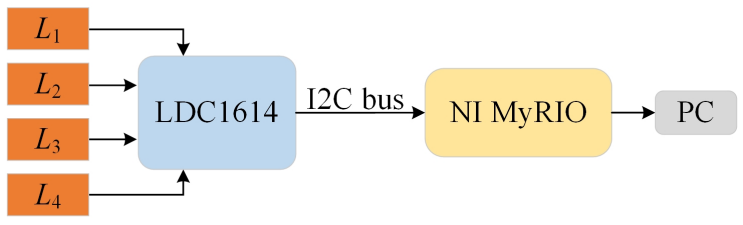

Fig. 9: The electrical interface for the developed tri-axis inductive sensor.

\section{Experimental Set-up}

To characterize and evaluate the sensor prototype, an experimental setup was developed to apply multi-axis loading to the sensor. This consists of three linear translation stages (MTS50-Z8, Thorlabs Inc., UK) in the configuration shown in Fig. 10. The translation stages are controlled by singlechannel DC servo motor controllers (KDC101, Thorlabs Inc., UK), providing a travel range of $50 \mathrm{~mm}$ along each motor axis. This system can move at the velocity up to $2.4 \mathrm{~mm} / \mathrm{s}$. The minimum repeatable incremental movement is $0.8 \mu \mathrm{m}$ and the repeatability is $1.6 \mu \mathrm{m}$ for bidirectional motion. A commercially available 6-axis force/torque sensor (Nano25, ATI Industrial Automation Inc., Apex, NC, USA) was used as a load reference for the calibration and evaluation of the sensor prototype. It has a force measurement range of $\pm 250 \mathrm{~N}$ in the $\mathrm{x} / \mathrm{y}$-axis and $\pm 1000 \mathrm{~N}$ in the z-axis, with a resolution down to $21 \mathrm{mN}$. The full system, illustrated in Fig. 10, places the load cell and an indenter on the $\mathrm{Z}$ stage while the sensor prototype is fixed onto the $\mathrm{XY}$ stage. The system applies load to the sensor prototype through controlled displacement along the three axes as required. Motion in each axis is synchronized to allow off-axis loading of the sensor (e.g. through simultaneous movement in the $\mathrm{X}$ and $\mathrm{Z}$ axes). The resultant force obtained from the load cell is then used to calibrate the inductive sensor. A custom program was developed for measurement and control of the calibration system and logging the resultant data for post-processing (LabVIEW, National Instruments).

\section{Evaluation of the Sensor's Inductive Response}

An experimental study was undertaken to examine the sensor's inductance response within the operating volume and 


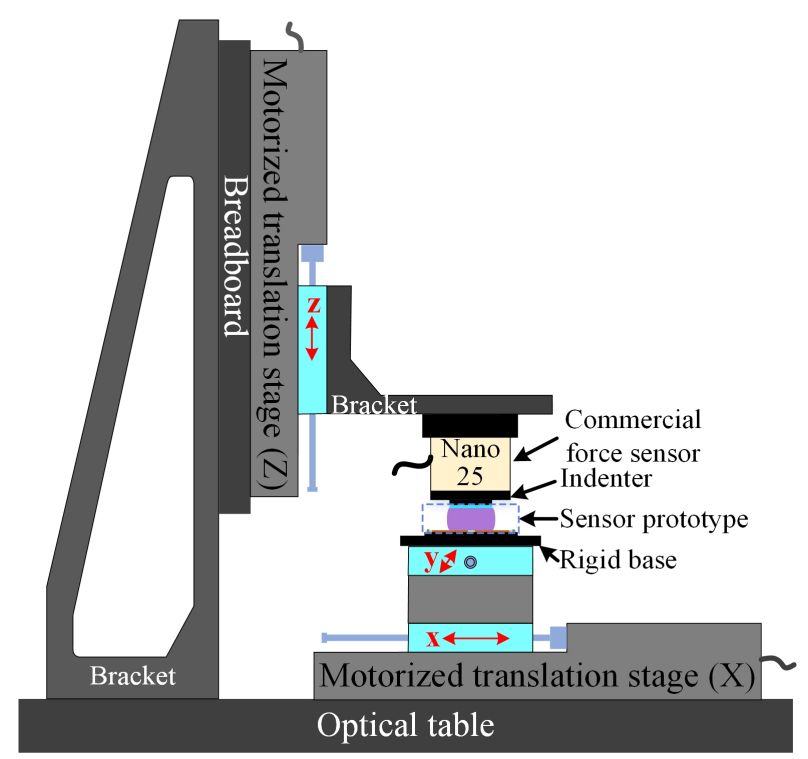

Fig. 10: Configuration of the multi-axis sensor calibration system.

validate the computational FE models (i.e. neglecting force load information). The target was fixed on the indenter and the coil system placed onto the rigid base. Elements were centeraligned and initially spaced $2 \mathrm{~mm}$ apart. The Z-axis translation stage was controlled to move the target from the initial position to $0.1 \mathrm{~mm}$ away from the sensing coils at an increment of 0.1 $\mathrm{mm}(d x=d y=0 \mathrm{~mm})$. The inductance of the sensing coils was measured after each increment was complete. This procedure was repeated five times. Similarly, the coils' responses to the lateral movement of the target was investigated in the range of $-2 \mathrm{~mm}$ to $2 \mathrm{~mm}$ with an increment of $0.1 \mathrm{~mm}(d z=0 \mathrm{~mm})$.

The inductance along each motion axis was computed and plotted in Fig. 11, together with the corresponding simulation results for comparison. It can be seen that the model results are in close agreement with the experimental data within these movement parameters. They demonstrate a maximum difference of $2.71 \% \mathrm{FS}$ and a root mean square error (RMSE) of $8.0 \mathrm{nH}$ to motion in the z-axis. In the $\mathrm{x}$-axis and $\mathrm{y}$-axis movements, the differences did not exceed $2.1 \%$ FS and $1.6 \%$ FS, and the RMSE was $5.6 \mathrm{nH}$ and $4.8 \mathrm{nH}$, respectively.

\section{E. Sensor Calibration for Force Measurement}

A calibration process was performed to characterize the sensor's response to applied external loads. The importance of rigorous calibration for this sensor is highlighted by the strong inter-axis coupling evident in the responses shown in Fig. 7(a) and Fig. 11. For example, for $d z=1, L_{x}$ varied 1.83 $\mu \mathrm{H}$ between $d x=-2: 2 \mathrm{~mm}$ but for $d z=2 \mathrm{~mm}$ it only changed $0.6 \mu \mathrm{H}$. This is typical of the response in each axis.

The calibration process used the multi-axis calibration system shown in Fig. 10. A 3D scanning process was conducted to fully investigate the relationship between coil inductance and applied force throughout the sensor operating volume. The volume was swept by stepping through each axis in $0.1 \mathrm{~mm}$ increments, led by increasing indentation from $d z=2 \mathrm{~mm}$ to
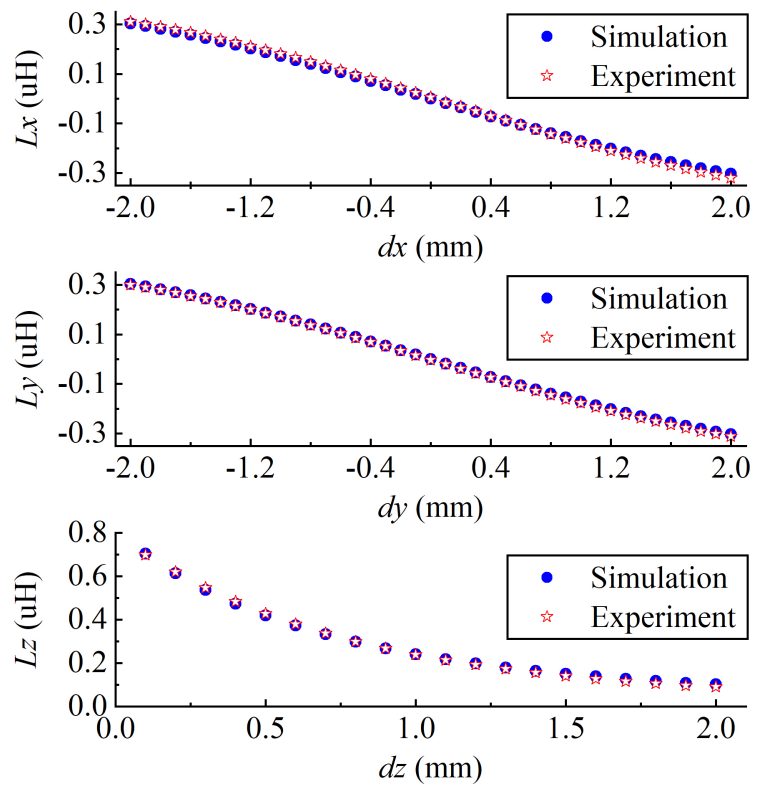

Fig. 11: Validation of the sensor's responses to the displacement variations along each axis.

$1.4 \mathrm{~mm}$, with $d x$ and $d y$ swept between $-1: 1 \mathrm{~mm}$ for each $d z$ setting. The coil inductances and resultant load were then recorded at each increment in a quasi-static fashion. Fig. 12 shows an example of the inductance response for all four coils as varying axial loading is applied to the sensor prototype. The coupled trend of the coils is clear, with slight inductance variations between the coils due to imperfect alignment of the inductive target (e.g. it is marginally off-centre at zero load).

Due to the complex relationship between the applied multiaxis force and measured inductance outputs, a two-layer feedforward neural network was selected to characterise the sensor [46]. The network is shown in Fig. 13(a), which comprises of 15 neurons in the hidden layer, the Tanh function as the activation function and the Levenberg-Marquardt backpropagation algorithm used as the training method. These features were selected based on prior research [47], [48] and preliminary testing for the identification of an appropriate structure. A total of 143172 data samples were obtained during the loading and unloading calibration process, of these $70 \%$ of the samples were used for training, $15 \%$ for validation, and the remaining $15 \%$ for testing.
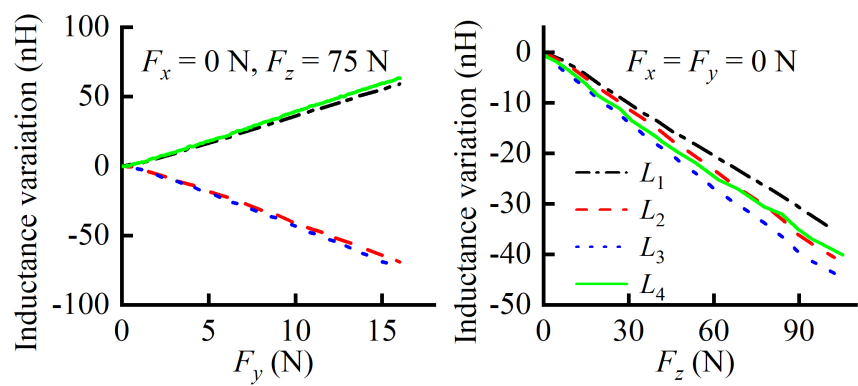

Fig. 12: An example of the variation in coil inductances under varying load. 
The estimated force output using the calibration neural network is presented in Fig. 13(b) (here $F_{x}$ is omitted because symmetry results in a similar distribution to $F_{y}$ ). As shown in Fig. 13(b), the shear load $F_{y}$ increased with increasing $d y$ and the absolute value of $F_{y}$ was maximum at the positions with $d y$ equal to $-1 \mathrm{~mm}$ or $1 \mathrm{~mm}$. The normal load increased as the target approached the sensing coils. In relation to the reference load cell, the readings of the sensor prototype present a RMSE of $1.05 \mathrm{~N}\left(F_{x}\right), 1.05 \mathrm{~N}\left(F_{y}\right)$, and $1.73 \mathrm{~N}\left(F_{z}\right)$. The larger deviation in $F_{z}$ may be co-related to temporal drift characteristics of the reference load cell (without loading this demonstrated a drift of $\sim 0.3 \mathrm{~N}$ and $0.1 \mathrm{~N}$ over 2 hours in normal and shear loading axes, respectively).

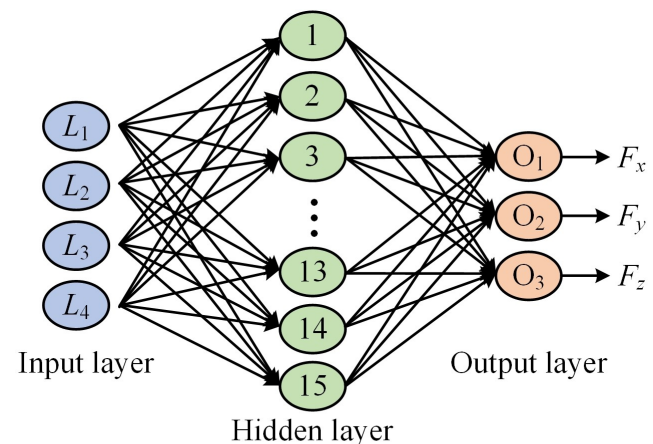

(a) Neural network model

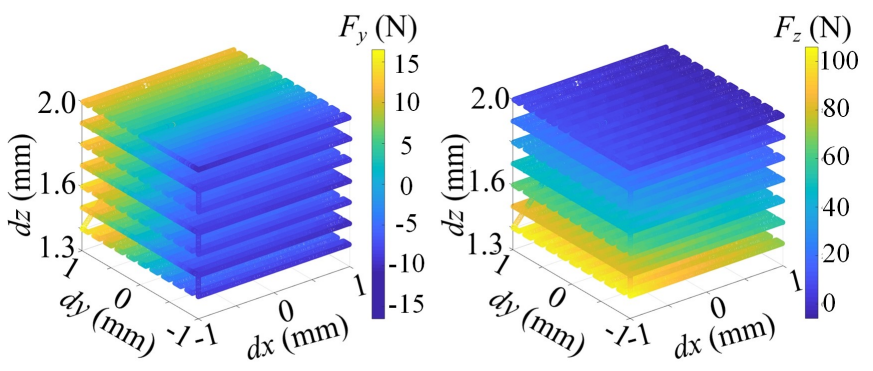

(b) Estimated shear and normal force load

Fig. 13: (a) Structure of the two-layer neural network model used to calibrate sensor output, (b) estimated normal and shear load using the Neural Network model in the defined movement volume.

\section{F. Sensor Evaluation for Force Measurement}

To assess the capability of the sensor prototype for measuring external load, tests were carried out to characterise the sensor, comprising temporal drift, hysteresis, and dynamic response.

1) Temporal drift of the sensor prototype: To evaluate the sensor's temporal stability, a range of multi-axis loads (between $10 \%-60 \% \mathrm{FS}$ for each axis) were applied to the sensor prototype for 180 min while the sensor output inductances were measured and converted into force values using the calibration neural network. In these tests, the sensor prototype showed variations typically no more than $3 \mathrm{mN}$ for $F_{x}$ and $F_{y}$ $(0.02 \% \mathrm{FS})$ and $6 \mathrm{mN}$ for $F_{z}(0.01 \% \mathrm{FS})$, indicating that the sensor prototype has low temporal drift. Fig. 14(a) presented the results obtained in one of these tests as a representative case.
2) Hysteresis of the sensor prototype: The sensor response is dependent on the compressible elastomer layer. Elastomeric materials are known to experience elastic hysteresis, typically due to internal material friction. We therefore evaluated the sensor hysteresis, achieved by applying a low frequency $(0.05$ $\mathrm{Hz}$ ) cyclic load to the sensor prototype. As shown in Fig. 14(b), the sensor prototype showed a maximum hysteresis of $4.7 \% \mathrm{FS}$ for the cyclic shear loading with an amplitude of $15.9 \mathrm{~N}$ and 5.8\%FS under normal loading (amplitude 105 $\mathrm{N})$, slightly higher than the hysteresis error of the soft sensor presented in [49] (4.3\% FS for normal loading) and [50] (3.2\% for normal loading and $4.0 \%$ for shear loading). These hysteresis properties can be altered and optimised through modification of the compressible layer, for example using different elastomeric materials. This is a topic of ongoing research within our group.

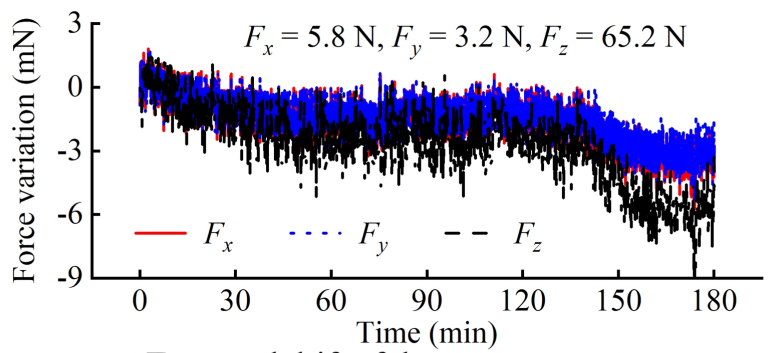

(a) Temporal drift of the sensor prototype.
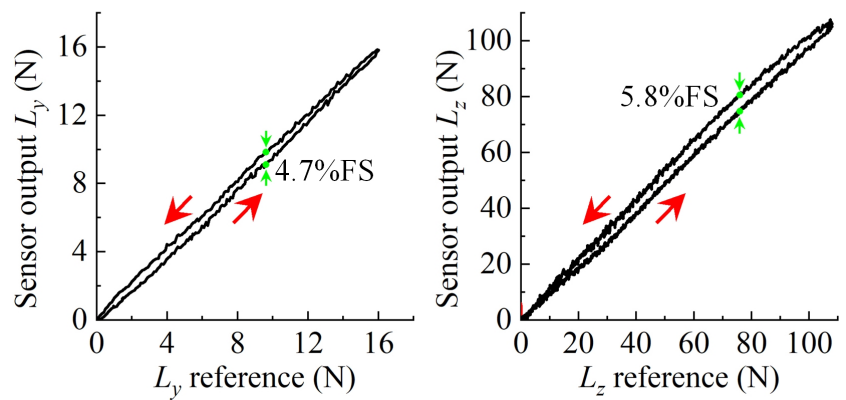

(b) Sensor responses to force loading-unloading cycle.

Fig. 14: (a) Temporal (drift) response of the sensor prototype under multi-axis loading for 180 minutes, (b) Hysteresis response of the sensor to shear and normal loading-unloading cycles.

3) Sensor dynamic response: The dynamic response of the sensor prototype is important for its practical application to monitor plantar load across the foot during daily activities. The literature shows that people walk with different stride frequencies but usually in the range of $1.4-2.5 \mathrm{~Hz}$ [51]. When running, stride frequency can be up to $4.8 \mathrm{~Hz}$ [52]. Therefore, tests were conducted to investigate the dynamic response of the sensor under different load regimes. The multi-axis load response was explored using the multi-axis calibration system (Fig. 10). The three axes were swept simultaneously at a velocity of $0.25 \mathrm{~mm} / \mathrm{s}$ (about $0.17 \mathrm{~Hz}$ ) to produce a varying tri-axis load to the sensor prototype across the operating load range. The sensor output inductances were measured at $100 \mathrm{~Hz}$ and converted into corresponding force values. Fig. 15 presents these data, together with the applied load determined by the reference load cell. It is evident that the calibrated sensor 
exhibits close agreement to the reference, showing an RMSE of $0.26 \mathrm{~N}$ for $F_{x}$ measurements and $1.37 \mathrm{~N}$ for $F_{z}$. Some significant variations were observed at points of peak force, likely due to increased hysteresis in the elastomeric layer of the sensor in comparison to the reference load cell which uses silicon strain gauges.
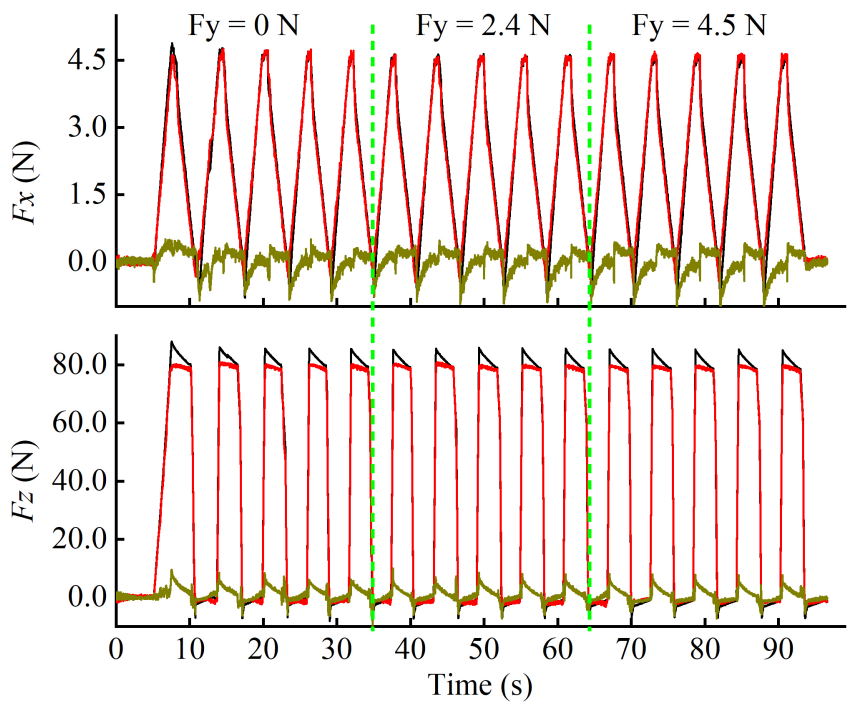

- Nano25 - Sensor prototype - Variation

Fig. 15: Responses of the sensor prototype and the commercial force sensor (Nano25) to the varied tri-axis load.

We further evaluated dynamic performance at increased frequencies using a dynamic loading instrument (Instron ElectroPuls $^{\mathrm{TM}}$ E10000 with load cell 105393, capable of performing motion up to $100 \mathrm{~Hz}$ ). This system is limited to single-axis motion, so a cyclic normal load was applied to the sensor prototype. The system was configured under position control mode to successively apply triangular waveforms across frequencies of $1 \mathrm{~Hz}, 3 \mathrm{~Hz}, 6 \mathrm{~Hz}$ and $10 \mathrm{~Hz}$. The applied load and the sensor outputs were measured simultaneously at a sample rate of $250 \mathrm{~Hz}$. As shown in Fig. 16, the sensor prototype closely followed the load profile across the tested frequencies of $1 \mathrm{~Hz}, 3 \mathrm{~Hz}, 6 \mathrm{~Hz}$, and $10 \mathrm{~Hz}$, demonstrating an RMSE of $1.55 \mathrm{~N}, 1.69 \mathrm{~N}, 1.81 \mathrm{~N}$, and $2.76 \mathrm{~N}$, respectively. Phase lag is negligible at these operating frequencies. In each cycle, a plateau is evident at the position where $F_{z}=0 \mathrm{~N}$ where the indenter briefly loses contact with the sensor. The sensor's response to multi-axis loading at these higher frequencies will be explored using specialized equipment in future work.

\section{DISCUSSION}

This paper demonstrates how multi-axis inductive sensing technology can be readily tailored toward a specific application, in this instance to address the clinical need of measuring foot loading to assess diabetic foot ulceration. This involves firstly mapping the clinical needs to a set of technical specifications, and secondly understanding how (and if) these can be achieved given the sensor's design parameters and constraints. 3D FE modelling has formed the core of the design and optimization process to ensure the sensor is appropriate for plantar load measurement. As presented in section III, the developed 3D model provides a tool to understand the influence of the design parameters including symmetric and non-symmetric configuration of multiple coils, their individual design, and electrical energization of the coil system. Validation of the model showed that the simulated results from these 3D models were consistent with the response from a representative experimental configuration (see Fig. 11). Using this model-based optimization approach has facilitated the navigation of complex and coupled mechanical, electrical and electromagnetic factors which comprise the sensor's designspace. The arrangement of four-square sensing coils with maximal turns was found to be the most suitable design for the requirements of plantar load measurement which has the particular need for sensitivity in both normal and shear loading. The 3D model also helped define the sensor's effective operating volume $(-2 \mathrm{~mm}<d x, d y<2 \mathrm{~mm}, d z<2 \mathrm{~mm})$ based on the sensitivity constraints and sensor size requirements for effective measurement of plantar load.

The tri-axis sensor produces a non-linear response between applied load and the direct measurements of coil inductance, combined with strong inter-axis coupling. Calibration therefore requires careful consideration of these characteristics. Our previous work has employed genetic algorithms [31] but here a two-layer feed-forward neural network model was found to provide a superior response, in particular the avoidance of overfitting characteristics. Experimental evaluation (see Fig. 13 and Fig. 15) demonstrate that the neural network approach successfully decoupled the sensor outputs to provide an accurate mapping to the applied load. The same trained neural network can then be applied to calibrate each sensing node in an array because they act as independent elements (as shown in Fig. 8). This approach provides a computationally efficient solution to calibration of the sensing array; the training process is computationally expensive but needs only be conducted once and prior to use, subsequently it is feasible to reconstruct output loads online using the trained neural network on an embedded system.

The optimized and calibrated sensor prototype successfully meets the essential requirements for plantar load measurement shown in Table I. As demonstrated in Fig. 13(b), the sensor is capable of measuring a normal load of 0-105 $\mathrm{N}$ (equivalent to $0-1047 \mathrm{kPa}$ pressure, the perpendicular component of force per unit area over which the force is distributed) and shear load from $-16 \mathrm{~N}$ to $16 \mathrm{~N}$ (equivalent to $-160-160 \mathrm{kPa}$ shear stress, the horizontal component of force per cross-sectional area). This outperforms the measurement range of similar tri-axis force sensors reported for plantar load detection in the literature [26] (131 $\mathrm{kPa}$ in each axis), [27] (250 kPa for pressure and $31 \mathrm{kPa}$ for shear axes), [28] (11.8 $\mathrm{kPa}, 11.3 \mathrm{kPa}$, and $15.7 \mathrm{kPa}$ in the $\mathrm{x}-, \mathrm{y}-$, and $\mathrm{z}$-axis, respectively), and [31] (84.5 $\mathrm{kPa}$ for pressure and $9.1 \mathrm{kPa}$ for shear stress). The size of the sensor is also critical and the reported prototype has overall dimensions of $15 \mathrm{~mm} \times 15 \mathrm{~mm} \times 2.5 \mathrm{~mm}$, comparing favourably to the sensors reported above. In addition, the sensor prototype presented appropriate characteristics for load measurement with low drift (high temporal stability, see Fig. 


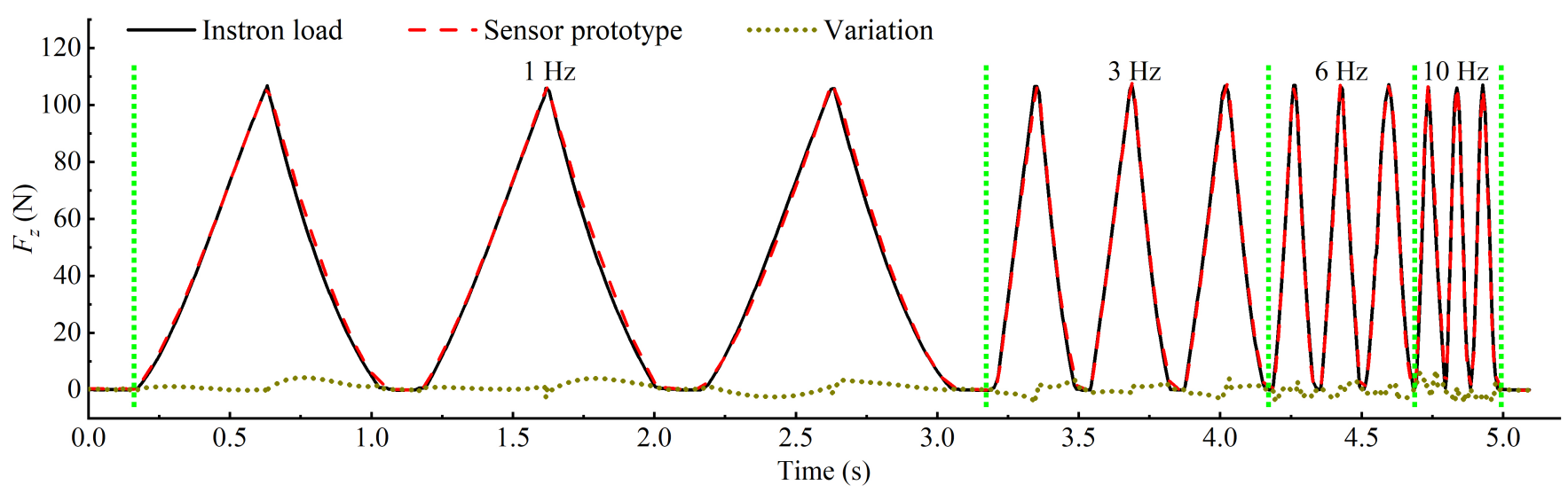

Fig. 16: Response of the sensor prototype to cyclic normal force load with a frequency of $1 \mathrm{~Hz}, 3 \mathrm{~Hz}, 6 \mathrm{~Hz}$, and $10 \mathrm{~Hz}$.

14(a)) and a good dynamic response in the target frequency range (see Fig. 15 and Fig. 16). These traits indicate the strong potential for this sensing technique to be used for plantar load measurement of the foot.

The main limitations of the sensor presented here relate to performance and robustness. At $2.5 \mathrm{~mm}$ thick, the sensor prototype presented here operates at the outer limit of the operating volume defined in section III.C $(-2 \mathrm{~mm} \leq d x, d y$ $\leq 2 \mathrm{~mm}, 0<d z \leq 2 \mathrm{~mm}$ ), limiting sensitivity. The overall thickness is dominated by the $2 \mathrm{~mm}$ thick elastomer layer. In this phase of research, a manual molding technique was used to fabricate the elastomer layer, placing a constraint on creating thinner layers. However, alternative semi-automated processes (e.g. using 3D printing and vacuum casting) can readily achieve consistent $<2 \mathrm{~mm}$ elastomer layers and provide a future means to reduce sensor thickness. This would bring improved sensor sensitivity (see Fig. 7) and reduce the sensor profile to be comparable to that of commercial load measurement insoles. For context, Tekscan's F-Scan system uses thinfilm approaching $0.15 \mathrm{~mm}$ thickness but is not intended for sustained long-term use, more comparable is Novel.de's Pedar system at $1.9 \mathrm{~mm}$ thick. Using a similar configuration for this sensor technology would enable integration within an insole to ensure robustness for longevity while maintaining comfort. In conjunction, electrical robustness and wiring complexity are key challenges with this sensing technology, particularly when scaling up towards the target application of an array of sensors embedded within an insole. In this configuration, each sensing node will be spaced a few millimeters apart and each sensor's coils will be activated and measured sequentially to minimize mutual coupling and interference. To mitigate the effects of wiring complexity, we are exploring the combination of sensing coils and associated measurement electronics within an integrated PCB [53].

The focus of this current work has been to develop an appropriate 'sensing unit' that can form the basis of an inshoe sensing array. The next stage of our research will be to develop and evaluate an integrated in-shoe sensing array. This will encompass further application specific evaluation including the sensor's dynamic response to multi-axis loading within a composite insole structure, aging effects, sensitivity to the operating environment (e.g. temperature and humidity associated within a shoe), the arrangement of elements within the sensing array to ensure appropriate coverage of the plantar surface and reconstruction of the distributed load applied to the insole using the response from the sensing array, and intersensor variability (e.g. as a result of fabrication inconsistencies) and their correction using biasing techniques [54], [55]. It is pertinent to address and evaluate these aspects as an integrated system, since they are tightly coupled. For example, encapsulation of sensing elements within other materials for environmental protection will affect the sensor's dynamic response. Thus, this work represents a promising first step in the journey towards using inductive sensing technology for multi-axis plantar load measurement and the assessment of diabetic foot disorders.

\section{CONCLUSION}

This paper reports the design and the performance of a soft tri-axis inductive force sensor, the first of its kind suitable for simultaneous measurement of plantar normal and shear load. A 3D FE model was developed and validated as a valuable tool with which to optimise the sensor design parameters. A coil configuration using four-square coils with maximal turns in the specified sensing area outperformed other alternatives, showing both a high sensitivity to tri-axis loading and a high sensing quality-factor 'Q'. A neural network model was used to successfully calibrate the sensor and account for strong inter-axis coupling between the directly measured inductance parameters. Validation showed a close mapping between measured and applied loading. The final sensor prototype was fabricated with a dimension of $15 \mathrm{~mm} \times 15 \mathrm{~mm} \times 2.5$ $\mathrm{mm}$ and could measure normal load up to $105 \mathrm{~N}$ (equivalent to $1047 \mathrm{kPa}$ pressure) and shear load in the range of -16 $\mathrm{N}$ to $16 \mathrm{~N}$ (equivalent to $-160-160 \mathrm{kPa}$ shear stress) with a high temporal stability and a good dynamic response at target frequencies. This meets the expected load and spatial resolution requirements for measurement of multi-axis plantar loading. Overall, the reported tri-axis force sensor shows promise for use as an in-shoe load sensing node to assess people at risk of diabetic foot ulceration. 


\section{APPENDIX}

\section{A. Coil model design and performance simulation}

In ANSYS Maxwell 3D module, basic structures can be created using geometric primitives together with geometry operations. Designing coils with a complex structure is a challenge with the built-in geometric tools, but a model can be designed externally and imported into the Maxwell package. We design the coil model and carry out the simulations following the steps below.

1) Develop a 3D model of the sensing coils in a CAD package and export in STEP format.

2) Import the 3D coil object into ANSYS Maxwell 3D environment.

3) Check the imported model. If the 3D coil model is an assembly drawing, each part will be imported as an individual geometric object in ANSYS Maxwell 3D. The relevant objects need to be united as a complete model. See Fig A1.

4) Create a boundary box surrounding the coils for simulation.

5) Bring the coil terminals out to touch the boundary edges.

6) Set the solution type, assign materials, excitations, mesh, and parameters for the coil objects, and add solution setup for analysis.

7) Set Optimetrics if necessary.

8) Perform a validation check before analysing the model.

9) Evaluate the simulated results.

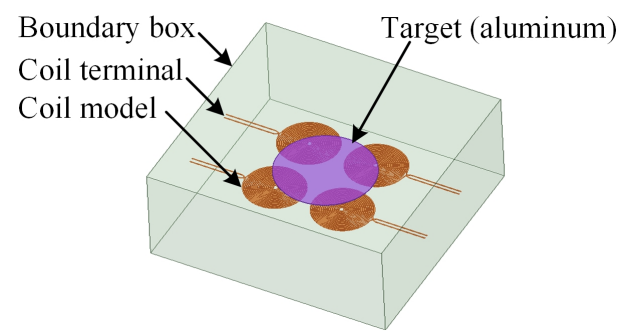

Fig. A1: 3D simulation model of a sensing coil design in ANSYS Maxwell environment

\section{B. Coil design for prototype fabrication}

According to the following steps, the electronic circuit design was performed for coil prototype fabrication.

1) Develop 3D coil model in SolidWorks.

2) Save the coil design as a DXF/DWG file (all splines need to be exported as polylines). Before saving the DXF/DWG file, either the inner edges or the outer edges of the coil traces need to be deleted to get a single spiral trace line.

3) Import the coil files into PCB design software (e.g. Altium Designer).

4) Add soldering pads, vias, and extra traces for connection using the design tools in PCB software. If there exist some other components in the circuit design, all the electrical connections have to be finished before fabrication.

\section{Coil parameters}

The parameters of the circular and square coils investigated in section III.A, including the pitch $(P)$, the trace width $\left(T_{w}\right)$, and the resultant trace length $(L)$, are listed in Table A. 1 (unit: $\mathrm{mm})$.

TABLE A1: Parameters of the circular and square coils studied in section III.A.

\begin{tabular}{|l|l|l|l|l|l|l|l|l|}
\hline \multicolumn{5}{|c|}{ Circular coils } & \multicolumn{5}{c|}{ Square coil } \\
\cline { 2 - 10 }$T_{w}$ & 0.075 & 0.1 & 0.2 & 0.3 & 0.075 & 0.1 & 0.2 & 0.3 \\
\hline 0.075 & 252 & 217 & 138 & 102 & 331 & 285 & 186 & 139 \\
\hline 0.1 & 215 & 188 & 126 & 94 & 284 & 250 & 170 & 130 \\
\hline 0.2 & 133 & 122 & 92 & 74 & 179 & 166 & 127 & 103 \\
\hline 0.3 & 95 & 89 & 71 & 59 & 130 & 124 & 101 & 86 \\
\hline 0.4 & 72 & 69 & 58 & 49 & 102 & 98 & 84 & 73 \\
\hline 0.5 & 58 & 56 & 48 & 42 & 84 & 81 & 71 & 64 \\
\hline 0.6 & 48 & 47 & 41 & 36 & 71 & 69 & 62 & 56 \\
\hline 0.7 & 41 & 38 & 35 & 31 & 62 & 58 & 54 & 50 \\
\hline 0.8 & 35 & 34 & 30 & 29 & 54 & 53 & 49 & 44 \\
\hline 0.9 & 30 & 30 & 28 & 25 & 48 & 48 & 43 & 41 \\
\hline
\end{tabular}

\section{ACKNOWLEDGMENT}

The research is supported by the National Institute for Health Research (NIHR) infrastructure at Leeds. The views expressed are those of the author(s) and not necessarily those of the NHS, the NIHR or the Department of Health and Social Care.

The authors would like to thank the NIHR MedTech and In Vitro diagnostics Co-operatives (MICs).

\section{REFERENCES}

[1] Diabetes.co.uk, Diabetes Prevalence, (accessed on: Apr. 03, 2019). [Online]. Available: https://www.diabetes.co.uk/diabetes-prevalence.html

[2] Z. Xu and X. Ran, "Diabetic foot care in China: challenges and strategy," Lancet Diabetes Endocrinol., vol. 4, no. 4, pp. 297-298, Apr. 2016.

[3] M. Kerr, Diabetic foot care in England: An economic study, Jan. 2017.

[4] M. Kerr, IDF Diabetes ATLAS 8th edition, 2017.

[5] A. J. Boulton, "Pressure and the diabetic foot: clinical science and offloading techniques," Am. J. Surg., vol. 187, no. 5, pp. S17-S24, May 2004.

[6] A. Veves, H. Murray, M. Young, and A. Boulton, "The risk of foot ulceration in diabetic patients with high foot pressure: a prospective study," Diabetologia, vol. 35, no. 7, pp. 660-663, Jul. 1992.

[7] N. Singh, D. G. Armstrong, and B. A. Lipsky, "Preventing foot ulcers in patients with diabetes," Jama, vol. 293, no. 2, pp. 217-228, Jan. 2005.

[8] R. M. Stess, S. R. Jensen, and R. Mirmiran, "The role of dynamic plantar pressures in diabetic foot ulcers," Diabetes care, vol. 20, no. 5, pp. 855-858, May 1997.

[9] M. Yavuz, "Plantar shear stress distributions in diabetic patients with and without neuropathy," Clin. biomech. (Bristol, Avon), vol. 29, no. 2, p. 223, 2014.

[10] M. Yavuz, H. Master, A. Garrett, L. A. Lavery, and L. S. Adams, "Peak plantar shear and pressure and foot ulcer locations: a call to revisit ulceration pathomechanics," Diabetes Care, vol. 38, no. 11, pp. e184e185, Nov. 2015.

[11] M. Yavuz, A. Ersen, J. Hartos, B. Schwarz, A. G. Garrett, L. A. Lavery, D. K. Wukich, and L. S. Adams, "Plantar shear stress in individuals with a history of diabetic foot ulcer: an emerging predictive marker for foot ulceration," Diabetes care, vol. 40, no. 2, pp. e14-e15, Feb. 2017.

[12] M. Yavuz, A. Erdemir, G. Botek, G. B. Hirschman, L. Bardsley, and B. L. Davis, "Peak plantar pressure and shear locations: relevance to diabetic patients," Diabetes Care, vol. 30, no. 10, pp. 2643-2645, Oct. 2007. 
[13] M. Lord and R. Hosein, "A study of in-shoe plantar shear in patients with diabetic neuropathy," Clin. Biomech., vol. 15, no. 4, pp. 278-283, May 2000

[14] A. Amemiya, H. Noguchi, M. Oe, H. Sanada, and T. Mori, "Establishment of a measurement method for in-shoe pressure and shear stress in specific regions for diabetic ulcer prevention," in 2016 IEEE 38th Annu. Int. Conf. IEEE Eng. Med. Biol. Soc. (EMBC), Orlando, FL, USA, pp. 2291-2294.

[15] novel.de, The pedar ${ }^{\circledR}$ system, Munich, Germany, (accessed on Apr. 16 2019). [Online]. Available: http://novel.de/novelcontent/pedar

[16] Tekscan, Inc., F-Scan ${ }^{T M}$ System, South Boston, MA, USA, (accessed on Apr. 16 2019). [Online]. Available: https://www.tekscan.com/productssolutions/systems/f-scan-system

[17] T\&T medilogic Medizintechnik GmbH, medilogic WLAN insole, Schönefeld, Germany, (accessed on Apr. 16 2019). [Online]. Available: https://medilogic.com/en/medilogic-wlan-insole/

[18] Universitat Politècnica de Valècia, Biofoot / IBV system, Valencia, Spain, (accessed on Apr. 16 2019). [Online]. Available: https://www.ibv.org/productos-y-servicios/productos/aplicacionesbiomecanicas/biofootibv-sistema-de-plantillas-instrumentadas-para-elanalisis-de-las-presiones-plantares

[19] BTS Bioengineering Corp., P-Walk Modular platforms system for plantar pressure measurement, Quincy, MA, USA, (accessed on Apr. 16 2019). [Online]. Available: https://www.btsbioengineering.com/ products/p-walk/

[20] novel.de, The emed ${ }^{\circledR}$-systems, Munich, Germany, (accessed on Apr. 16 2019). [Online]. Available: http://novel.de/novelcontent/emed

[21] Tekscan, Inc., MatScan ${ }^{T M}$ Pressure Mat System, South Boston, MA, USA, (accessed on Apr. 16 2019). [Online]. Available: https://www.tekscan.com/products-solutions/systems/matscan

[22] RSscan International NV, footscan ${ }^{\circledR}$ systems, Belgium, (accessed on Apr. 16 2019). [Online]. Available: https://rsscan.com/footscan/

[23] M. Yavuz, G. Botek, and B. L. Davis, "Plantar shear stress distributions Comparing actual and predicted frictional forces at the foot-ground interface," J. Biomech., vol. 40, no. 13, pp. 3045-3049, 2007.

[24] Innovative Scientific Solutions, Inc., FootSTEPS Gait Analysis System, Dayton, OH, USA, (accessed on Aug. 15 2019). [Online]. Available: https://innssi.com/footsteps/

[25] S. Rajala and J. Lekkala, "Plantar shear stress measurements-A review," Clin. Biomech., vol. 29, no. 5, pp. 475-483, Mar. 2014.

[26] H.-K. Lee, J. Chung, S.-I. Chang, and E. Yoon, "Normal and shear force measurement using a flexible polymer tactile sensor with embedded multiple capacitors," J. Microelectromech. Syst., vol. 17, no. 4, pp. 934 942, 2008

[27] G. Liang, Y. Wang, D. Mei, K. Xi, and Z. Chen, "Flexible capacitive tactile sensor array with truncated pyramids as dielectric layer for threeaxis force measurement," J. Microelectromech. Syst., vol. 24, no. 5, pp. 1510-1519, Oct. 2015.

[28] S. Wattanasarn, K. Noda, K. Matsumoto, and I. Shimoyama, "3D flexible tactile sensor using electromagnetic induction coils," in 2012 IEEE 25th Int. Conf. Micro Electro Mechanical Systems (MEMS), Paris, France, pp. $488-491$.

[29] L. Du, X. Zhu, and J. Zhe, "An inductive sensor for real-time measurement of plantar normal and shear forces distribution," IEEE Trans. Biomed. Eng., vol. 62, no. 5, pp. 1316-1323, May 2015.

[30] H. Wang, J. Kow, N. Raske, G. de Boer, M. Ghajari, R. Hewson, A. Alazmani, and P. Culmer, "Robust and high-performance soft inductive tactile sensors based on the eddy-current effect," Sens. Actuators A Phys., vol. 271, pp. 44-52, Mar. 2018.

[31] H. Wang, D. Jones, G. de Boer, J. Kow, L. Beccai, A. Alazmani, and P. Culmer, "Design and characterization of tri-axis soft inductive tactile sensors," IEEE Sens. J., vol. 18, no. 19, pp. 7793-7801, Oct. 2018.

[32] S. Ostadabbas, A. Saeed, M. Nourani, and M. Pompeo, "Sensor architectural tradeoff for diabetic foot ulcer monitoring," in 2012 Annu. Int. Conf. IEEE Eng. Med. Biol. Soc., San Diego, CA, USA, pp. 6687-6690.

[33] B. L. Davis, J. E. Perry, D. C. Neth, and K. C. Waters, "A device for simultaneous measurement of pressure and shear force distribution on the plantar surface of the foot," J. Appl. Biomech., vol. 14, no. 1, pp. 93-104, Feb. 1998

[34] M. A. Razian and M. G. Pepper, "Design, development, and characteristics of an in-shoe triaxial pressure measurement transducer utilizing a single element of piezoelectric copolymer film," IEEE Trans. Neural Syst. Rehabil. Eng., vol. 11, no. 3, pp. 288-293, Sept. 2003.

[35] A. Razak, A. Hadi, A. Zayegh, R. K. Begg, and Y. Wahab, "Foot plantar pressure measurement system: A review," Sensors, vol. 12, no. 7, pp. 9884-9912, 2012
[36] S. S. Zulkifli and L. W. Ping, "A state-of-the-art review of foot pressure," Foot Ankle Surg., Dec. 2018, in press.

[37] Texas Instruments, LDC1614, 4-channel, 28-bit Inductance-to-Digital Converter with I2C for Inductive Sensing, (accessed on: Apr. 03, 2019). [Online]. Available: http://www.ti.com/product/LDC1614

[38] I. Schmidt and A. Enders, "Characterization and concept for optimization of planar spiral high power high frequency coils," in 2009 IEEE Int. Symp. Electromagn. Compat., Austin, TX, USA, pp. 24-28.

[39] U.-M. Jow and M. Ghovanloo, "Modeling and optimization of printed spiral coils in air, saline, and muscle tissue environments," IEEE Trans. Biomed. Circuits Syst., vol. 3, no. 5, pp. 339-347, 2009.

[40] Q. Yu and T. W. Holmes, "Stray capacitance modeling of inductors by using the finite element method," in 1999 IEEE Int. Symp. Electromagn. Compat., vol. 1, Tokyo, Japan, pp. 305-310.

[41] M. J. Warren-Forward, R. M. Goodall, and D. J. Pratt, "Threedimensional displacement and force transducer," IEE Proc. A Science, Measurement and Technology, vol. 139, no. 1, pp. 21-29, Jan. 1992.

[42] S.-K. Yeh and W. Fang, "Inductive micro tri-axial tactile sensor using a CMOS chip with a coil array," IEEE Electron Device Lett., vol. 40, no. 4, pp. 620-623, Apr. 2019.

[43] C. Oberhauser, LDC sensor design, (accessed on: Apr. 03, 2019). [Online]. Available: http://www.ti.com/lit/an/snoa930a/snoa930a.pdf

[44] J. C. Case, E. L. White, and R. K. Kramer, "Soft material characterization for robotic applications," Soft Robotics, vol. 2, no. 2, pp. 80-87, 2015.

[45] National Instruments Corp., myRIO Student Embedded Device myRIO-1900, Austin, TX, USA, (accessed on Apr. 22 2019). [Online]. Available: https://www.ni.com/en-gb/shop/select/ myrio-student-embedded-device?modelId $=125751$

[46] G. Bebis and M. Georgiopoulos, "Feed-forward neural networks," IEEE Potentials, vol. 13, no. 4, pp. 27-31, 1994

[47] H. Yu and B. M. Wilamowski, "Levenberg-marquardt training," Ind. Electron. hb., vol. 5, no. 12, p. 1, 2011.

[48] A. K. Jain, J. Mao, and K. M. Mohiuddin, "Artificial neural networks: A tutorial," Computer, vol. 29, no. 3, pp. 31-44, 1996.

[49] K. Kim, S. Shin, and K. Kong, "An air-filled pad with elastomeric pillar array designed for a force-sensing insole," IEEE Sens. J., vol. 18, no. 10 , pp. 3968-3976, 2018.

[50] J. Park, S. J. Kim, Y. Na, Y. Kim, and J. Kim, "Development of a bendable outsole biaxial ground reaction force measurement system," Sensors, vol. 19, no. 11, p. 2641, 2019.

[51] T. Ji and A. Pachi, "Frequency and velocity of people walking," Struct. Eng., vol. 84, no. 3, pp. 36-40, 2005.

[52] M. Krzysztof and A. Mero, "A kinematics analysis of three best $100 \mathrm{~m}$ performances ever," J. Hum. Kinet., vol. 36, no. 1, pp. 149-160, 2013.

[53] L. Wang, D. Jones, G. J. Chapman, H. J. Siddle, D. A. Russell, A. Alazmani, and P. Culmer, "Design of a digital triaxial force sensor for plantar load measurements," in 2019 IEEE SENSORS, Montreal, QC, Canada, 2019, pp. 1-4.

[54] Ó. Oballe-Peinado, F. Vidal-Verdú, J. A. Sánchez-Durán, J. CastellanosRamos, and J. A. Hidalgo-López, "Accuracy and resolution analysis of a direct resistive sensor array to FPGA interface," Sensors, vol. 16, no. 2, p. 181, 2016.

[55] J. Ye, Z. Lin, J. You, S. Huang, and H. Wu, "Inconsistency calibrating algorithms for large scale piezoresistive electronic skin," Micromachines, vol. 11 , no. 2 , p. $162,2020$. 